\title{
Dioxin food crises and new POPs: challenges in analysis
}

\author{
Jean-Françcois Focant
}

Published online: 16 February 2012

(C) Springer-Verlag 2012

\section{How it all started}

When more than a million broiler chickens suddenly and unexpectedly died in the eastern and midwestern parts of the United States in late 1957; the first dioxin crisis record was set [1]. It took nearly 10 years of investigation to pinpoint $1,2,3,7,8,9$ hexachlorodibenzo- $p$-dioxin as the hydropericardiumproducing factor, the responsive agent for the so-called chick edema disease [2]. This toxic material was present in by-product fatty acids incorporated in feed. Contaminated oleic and stearic acids originated from producers who used inedible tallow collected after hide-stripping operations during which dioxincontaminated pentachlorophenol was widely used as a hide preservative. This pentachlorophenol-related fatty acid contamination motivated the development of the first analytical method to measure selected polychlorinated dibenzo- $p$-dioxins (PCDDs) and polychlorinated dibenzofurans (PCDFs) in animal fat samples [3]. The Yusho and Yu-Cheng catastrophes both confirmed the importance of controlling food processing to avoid dangerous episodes of human exposure via food consumption [4, 5]. The 1999 Belgian dioxin chicken-gate affair ultimately demonstrated the economic damage that could result from such a contamination episode, and pushed the European Union (EU) to start an efficient and pro-active monitoring program to ensure the proper quality of European food and feed

Published in the special paper collection Recent Advances in Food Analysis with guest editors J. Hajslova, R. Krska, M. Nielen.

J.-F. Focant $(\bowtie)$

CART, Organic and Biological Analytical Chemistry,

Chemistry Department, University of Liège,

Allée de la Chimie 3, B-6c Sart-Tilman,

4000 Liège, Belgium

e-mail: JF.Focant@ulg.ac.be and to try to maintain most of the population below tolerable weekly intake $[6,7]$.

Therefore, starting back in early 2000, the European Commission (EC) began to propose legislation and began implementation of decisions to regulate dioxin and dioxinlike (DL-)PCB levels in foodstuffs and animal feed [8]. The EC strategy relies on the coordination of actions at the EU level to implement continuous monitoring and produce comprehensive and reliable data. First, maximum residue levels (MRLs) were established for seventeen 2,3,7,8-substituted dioxins and furans only, and set as levels as low as reasonably achievable (ALARA), on the basis of the limited data available at that time [9]. The twelve DL-PCBs were later added for both food and feed to enable better toxicological evaluation [10-13]. Further establishment of action levels, levels which if exceeded by levels of PCDD/Fs ${ }^{1}$ and/ or DL-PCBs should initiate investigations to identify the source of contamination, later completed the strategy [14]. To efficiently protect consumers' health, a rapid alert system for food and feed (RASFF) was also introduced to ensure immediate notification to the EC if a member state had any information about a serious health risk related to $\mathrm{PCDD} / \mathrm{F}$ contamination derived from food or feed [15].

Originally, in early 2000, it was challenging to timely and cost-effectively perform food-feed control. All together, depending on the position and number of chlorine atoms present in the molecule, $\mathrm{PCDD} / \mathrm{Fs}$ and $\mathrm{PCBs}$ represent more

\footnotetext{
${ }^{1}$ The term "dioxins" is used in EC legislation documents to define a group of molecules comprising seven PCDDs and ten PCDFs. The term "PCDD/Fs" used in this manuscript defines the same group of molecules.
} 
than 400 individual molecules (congeners). If only a sub-set of 29 molecules (17 PCDD/Fs and 12 DL-PCBs) is of prime interest, they must still be separated from others that potentially bioaccumulate and from each other to ensure precise quantification and proper estimation of the global toxicity of the mixture (TEQ, toxic equivalent approach). Target levels are as low as picograms or femtograms (fg) per gram of matrix, with matrix-related interferences present at concentrations several orders of magnitude higher than the analytes of interest. For those reasons, a complex multi-step approach is required to:

1. extract the analytes from the matrix core;

2. separate undesirable interferences; and

3. finally isolate, separate, and quantify analytes of interest.

This used to result in long and expensive processing times that were not acceptable in the context of food-feed control for which food-safety agencies need high sample throughput and fast response strategies to efficiently deal with potential incidental dioxin exposure. Additionally, foodstuffs and feed cannot stay under inspection for a long period of time without generating unaffordable economic losses.

To ensure the adequate production of comprehensive and reliable data on the presence of PCDD/Fs and DL-PCBs in food and feed, at the EC level, a screening-confirmatory approach was, thus, soon adopted for the official control of the PCDD/F and DL-PCBs; this is still in place today [16, 17]. The idea was to enable the use of validated rapid screening methods of analysis to select samples with PCDD/F and DL-PCB levels above a threshold value to be then determined precisely by a validated confirmatory method (namely, gas chromatography coupled to sector highresolution mass spectrometry, GC-HRMS). Although not exclusively limited to it, current screening is mainly performed using chemical activated luciferase gene expression (CALUX) bioassays, a response-binding assay (RBA) based on the aryl hydrocarbon receptor (AhR) [18]. Table 1 gives some of the main characteristics of both screening and confirmatory approaches in early 2000 , at the time the EU strategy was implemented. Specific analytical criteria had to be developed for the CALUX to be properly used in the framework of selected contaminant measurement, taking into account differences between biological equivalent (BEQ) response, based on relative potency (REP) values of the assay, and toxic equivalent (TEQ) values, based on toxic equivalent factors (TEFs) used for the setting of MRLs [19]. Additional set up of specific BEQ cut-off values was also required to improve the assignment of the "suspected non-compliant" status [20]. Over time, analytical criteria became so tailor-made for this cell-based assay that use of any other biological assay, for example immunoassay, was rarely observed. Although GC coupled to low resolution (LR)MS is also officially usable for screening, cases when it is used in practice are very rare, because the quality criteria to fulfil are nearly the same as those for confirmatory GC-HRMS, except the fact of using a high-resolution sector mass analyzer. Additionally, the same types of isotope dilution standards have to be used, and the same level of effort is necessary in terms of sample preparation, irrespective of the use of LRMS or HRMS. Therefore, once GC-MS is considered, aiming for confirmatory rather than screening seems to be the right choice, because little additional investment is required to acquire a HRMS analyzer capable of reproducible measurement at sub-ppt levels and giving access to congener-specific data. Replacing HRMS by approximately half-price LRMS would actually not reduce the analytical cost by more than a few percent, particularly if large sample numbers are considered (Table 2).

\section{What is the situation today?}

More than ten years after implementation of the screeningconfirmatory approach, the analytical situation has evolved drastically (Table 1). Such an enhancement of analytical quality has been possible because the EC regulation was built on a performance-based measurement system (PBMS), suitable for analytical improvements, rather than on inflexible, locked, non-progressive procedures. The automation and hyphenation of parallel sample-preparation techniques enabled both cost and result delivery time to be significantly reduced for the confirmatory GC-HRMS method [21]. For selected matrices, it is common nowadays to have series of congener-specific data available in day +1 format (less than $30 \mathrm{~h}$ ) without even working with two labour shifts, which is significantly faster than performing screening. This obviously questions the real need to still performing screening rather than confirmatory analysis, especially for a suspected incident in which a large proportion of MRL non-compliant samples is to be expected. As soon as this proportion exceeds $35 \%$, direct confirmatory analysis is more cost-effective and further reduces the response time. Additionally, the availability of congenerspecific data rather than an estimate of a global level of contamination, is invaluable to trace the source of contamination and take rapid action. Because of this and because the EU confirmatory capacity $(n=27$ official or national reference laboratories, representing a capacity of approximately 1000 samples/week) is much larger than the screening capacity ( $n=$ 7 official or national reference laboratories, representing a capacity of approximately 300 samples/week), screening was not considered during a recent food incident [22]. Performing confirmatory analyses only for official regular food-feed control could also be considered because the cost difference between biological screening and the instrumental 
Table 1 Evolution of the analytical situation regarding the screening-confirmatory approach for measurement of $\mathrm{PCDD} / \mathrm{Fs}$ and DL-PCBs in food and feed

\begin{tabular}{|c|c|c|c|c|c|}
\hline & Cost (EUR) & Delivery (Days) & $\begin{array}{l}\text { High } \\
\text { Throughput }\end{array}$ & Congener-specific & $\begin{array}{l}\text { Biologicaly } \\
\text { relevant }\end{array}$ \\
\hline \multicolumn{6}{|l|}{ Early 2000} \\
\hline GC-HRMS & 900 & 5 & No & Yes & No \\
\hline RBA (CALUX) & 400 & 5 & Yes & No & No \\
\hline \multicolumn{6}{|l|}{ Early 2010} \\
\hline GC-HRMS & 400 & $1-3$ & Yes & Yes & No \\
\hline RBA (CALUX) & 250 & $2-4$ & Yes & No & No \\
\hline \multicolumn{6}{|l|}{ Early 2020} \\
\hline GC-HRMS & 300 & $1-2$ & Yes & Yes & No \\
\hline RBA (CALUX) & 125 & 1 & Yes & No & Yes \\
\hline
\end{tabular}

confirmatory method (especially when the reported cost of analysis per ton of food-feed ranges between 0.01 and 0.1 Euro) is so small for similar delivery times and throughput. In such conditions, it would defy logic not to produce congenerspecific data that are a crucial component of the action-level strategy that is supposed to be a key aspect of stimulating an active approach to reduce the presence of PCDD/Fs and DLPCBs in food and feed.

\section{What next for tomorrow?}

If the viability of biological screening can be questioned in the context of the implementation of congener-specific TEQ regulatory values, one should perhaps think back to what such assays are capable of offering in terms of global exposure information. Instead of spending time, money, and effort on tailored development of dioxin-dedicated sample-preparation procedures to ensure specificity and reduce the incidence of false positive results, RBAs could be used with minimal sample preparation. That would enable most toxicants present in the sample to interact with the AhR to give general toxicity information rather than an estimate limited to regulation compliance. This would be much more biologically relevant,

Table 2 Distribution of the analytical cost (\%) for both screening and confirmatory approaches for the measurement of PCDD/Fs and DLPCBs in food and feed

\begin{tabular}{lll}
\hline & Confirmatory by GC-HRMS & Screening by RBA \\
\hline Extraction & $10-15$ & $10-15$ \\
Clean-up & $15-20$ & $20-25$ \\
GC & $\leq 5$ & - \\
HRMS & $10-15$ & - \\
Standards & $\leq 5$ & $\leq 5$ \\
Cell culture & - & $10-15$ \\
Licence fee & - & $15-20$ \\
Personnel & $\approx 50$ & $30-40$ \\
\hline
\end{tabular}

because the assay mimics the biological process that is thought to be a significant part of the mechanism of dioxin-like toxicity. In that context, if the RBA procedure would be simplified and further automated, one could expect a $50 \%$ cut in prices (price distribution is summarized in Table 2). One could thus imagine that, in another 10-year period, the MRL control for PCDD/Fs and DL-PCBs would be performed exclusively by the instrumental method, simultaneously with widespread AhR-related screening for global toxicity assessment. This could be achieved at a price close to today's target analyses (Table 1). Such a dual approach would make the best use of each technique by applying them where they perform best.

This comprehensive method is actually needed if we want to enlarge current food safety practices to other known and unknown persistent organic pollutants (POPs). Samples with a large response in biological screening should be further analyzed in the hope of identifying new compounds. Efforts should be made to develop new instrumental analytical approaches that would enable us to extend the list of target compounds to more "exotic" (un)suspected persistent molecules present in our food. This more active and exhaustive approach is probably needed to more appropriately ensure a high level of food quality.

Major analytical challenges would then be at the level of instruments themselves. Both chromatographic resolution and instrumental limits of detection (iLODs) must be improved. Use of comprehensive two-dimensional GC $(\mathrm{GC} \times \mathrm{GC})[23,24]$ or cryogenic zone compression $(\mathrm{CZC})$ [25] GC coupled with HR time-of-flight MS (HRTOFMS) operating in full-scan (FS) mode [26] could appropriately complement classical GC-sector HRMS used in selected ion monitoring (SIM) mode for target analysis. This would lead to the possibility of screening for compounds other than the one under current regulation (organochlorine pesticides, halogenated flame retardants, GC-amenable perfluorinated compounds, ...), without any more work or additional sacrifice of sensitivity. Recent advances in coupling of $\mathrm{GC} \times \mathrm{GC}$ with HRTOFMS conveniently takes this approach one step further, because it enables elemental composition data to be 
obtained for unknown compounds present in complex mixtures. Furthermore, when considering halogenated compounds, a substantial improvement in sensitivity (down to low-fg iLODs) can be achieved by operating such a system in negative chemical ionization (NCI) rather than electronimpact (EI) mode.

Although so called "dioxin analyses" have been performed since mid-1970s, the need to control our exposure via foodfeed monitoring is still up to date. Analytical procedures have quite evolved to make such measurements more rapid and straightforward. Improving sensitivity and enlarging the task to other, emerging, compounds are probably the two most important challenges now. Several alternative approaches do exist and have some interesting features. The analytical chemistry of POPs has still some work ahead ...

Because of all the efforts made by the EU on aspects of both analytical and food-feed continuous control, one often says that Europe has one of the highest levels of food safety in the world. In the last few years only, several potential food incidents have been identified (e.g. citrus pulp pellets, recycled fats, mineral clays, choline chloride component, hydrochloric acid related to gelatine production, guar gum thickener, biodiesel-related fatty acids, ...) and related potential human exposure has been avoided. So far, however, only a very limited set of analytes has been included in those monitoring programs. What about all the other potentially harmful molecules present in our food that we do not look for? What about potential synergic or antagonistic effects of mixtures of untargeted toxicants? The question is still open.

\section{References}

1. Firestone D (1973) Environ Health Perspect 5:59-66

2. Cantrell JS, Webb NC, Mabis AJ (1969) Acta Cryst B25:150-156

3. Metcalfe LD (1972) J Assoc Off Anal Chem 55:542-546

4. Yoshimura T (2003) Ind Health 41:139-148

5. Hsu ST, Ma CI, Kwo-Hsiung S, Wu SS, Hsu NHM, Yeh CC (1984) Am J Ind Med 5:71-79

6. Bernard A, Hermans C, Broeckaert F, De Poorter G, De Cock A, Houins G (1999) Nature 401:231-232

7. Scientific Committee on Food, 2001. Opinion of the SCF on the risk Assessment of Dioxins and Dioxin-Like PCBs in Food. Report CS/CNTM/DIOXIN/20 Final

8. More information is available at http://ec.europa.eu/food/food/ chemicalsafety/contaminants/dioxins en.htm

9. Council Regulation (EC) No 2375/2001 of 29 November 2001 amending Commission Regulation (EC) No 466/2001 setting maximum levels for certain contaminants in foodstuffs. Off. J. Eur. Union, L321 (2001) 1

10. Commission Directive 2006/13/EC of 3 February 2006 amending Annexes I and II to Directive 2002/32/EC of the European Parliament and of the Council on undesirable substances in animal feed as regards dioxins and dioxin-like PCBs. Off. J. Eur. Union, L32 (2006) 44
11. Commission Regulation (EC) No 1881/2006 of 19 December 2006 setting maximum levels for certain contaminants in foodstuffs. Off J. Eur. Union, L364 (2006) 5

12. Commission Regulation SANCO/11248/2011 Rev. 2 amending Regulation (EC) No 1881/2006 as regards maximum levels for dioxins, dioxin-like PCBs and non dioxin-like PCBs in foodstuffs

13. Commission Regulation SANCO/11515/2011 amending Annexes I and II to Directive 2002/32/EC of the European Parliament and of the Council as regards maximum levels and action thresholds for dioxins and polychlorinated biphenyls

14. Commission Recommendation 2006/88/EC of 6 February 2006 on the reduction of the presence of dioxins, furans and PCBs in feedingstuffs and foodstuffs. Off. J. Eur. Union, L42 (2006) 26

15. Regulation (EC) No 178/2002 of 28 January 2002 laying down the general principles and requirements of food law, establishing the European Food. Off. J. Eur. Commun. L31, 1-24

16. Commission Regulation (EC) No 1883/2006 of 19 December 2006 laying down methods of sampling and analysis for the official control of levels of dioxins and dioxin-like PCBs in certain foodstuffs., Off. J. Eur. Union L364 (2006) 32

17. Commission Regulation (EC) No $152 / 2009$ of 27 January 2009 laying down the methods of sampling and analysis for the official control of feed. Off. J. Eur. Union. L54 (2009) 1

18. Windal I, Denison MS, Birnbaum LS, Van Wouwe N, Baeyens W, Goeyens L (2005) Environ Sci Technol 39:7357-7364

19. Behnisch PA, Hosoe K, Sakai S (2001) Environ Int 27:413-439

20. Commission Regulation SANCO/10557/2011, 2011

21. Focant J-F, Pirard C, De Pauw E (2004) Talanta 63:1101-1113

22. Esposito M, Serpe FP, Neugebauer F, Cavallo S, Gallo P, Colarusso G, Baldi L, Iovane G, Serpe L (2010) Chemosphere 79:341348

23. Focant J-F, Pirard C, Eppe G, De Pauw E (2005) J Chromatogr A 1067:265-275

24. Focant J-F, Eppe G, Scippo ML, Massart A-C, Pirard C, MaghuinRogister G, De Pauw E (2005) J Chromatogr A 1086:45-60

25. Patterson DG Jr, Welsch SM, Turner WE, Sjödin A, Focant J-F (2011) J Chromatogr A 1218:3274-3281

26. Shunji H, Yoshikatsu T, Akihiro F, Hiroyasu I, Kiyoshi T, Yasuyuki S, Masa-aki U, Akihiko K, Kazuo T, Hideyuki O, Katsunori A (2008) J Chromatogr A 1178:187-198

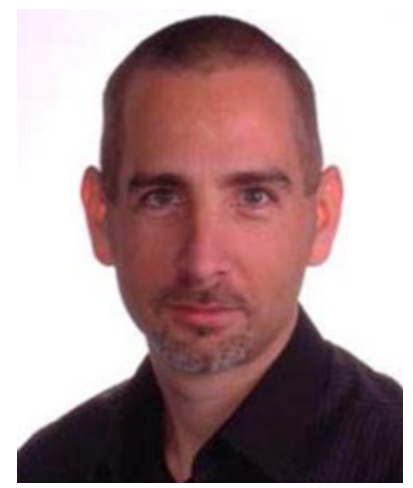

Jean-François (Jef) Focant is Associate Professor in the Chemistry Department of the University of Liège, Belgium. He has worked on the development and implementation of emerging analytical strategies for food control and human biomonitoring since the very beginning of his career. Known as a dioxin expert, he is also active in other areas of separation science, for example characterization of complex mixtures of volatile organic compounds (VOCs) for medical and forensic applications. Working on the hyphenation of state-of-the-art analytical techniques to solve practical analytical issues is what he enjoys doing most 